F. med. Genet. (1967). 4, 283.

\title{
Anomalies of Development in a Girl with Unusual Sex Chromosomal Mosaicism
}

\author{
MARIGOLD J. THORBURN, COLIN G. MILLER, and PETER DOVEY
}

From the Departments of Pathology and Paediatrics, The University of the West Indies, Famaica

Morphological abnormalities of the $\mathrm{X}$ chromosome are well documented and have been extensively reviewed and discussed by Ferguson-Smith (1965). They include isochromosome of the long arm, deletions of the long and short arms, ring chromosomes, and chromosomal fragments. Other types of abnormality are rare. Engel and Forbes (1965) described a chromatin negative girl (Patient No. 27) with a mosaicism of an XO line and an X large metacentric stem, which could have been an isochromosome. Mann, Valdmanis, Capps, and Puite (1965) described a girl with primary amenorrhoea who had an abnormality deduced to be due to a reciprocal translocation between an $X$ and a $B$ autosome, and Wie Lie, Coenegracht, and Stalder (1964) studied a mentally retarded girl with Turner's syndrome and a large metacentric chromosome replacing an $\mathrm{X}-6-12$ chromosome in all cells.

We here present a patient with some features of gonadal dysgenesis who was found to have mosaicism with an XO line and a 46 line, with a morphological abnormality, probably of an X chromosome. In addition, there were unusual radiological and electroencephalographic features.

\section{Case Report}

A Negro girl first presented at the paediatric clinic of the University College Hospital of the West Indies in August 1965, at the age of 9 years. She had a threeyear history of intermittent attacks of nausea, vomiting, and abdominal pain, accompanied by profuse sweating, cold extremities, and anxiety. These occurred mainly at night and usually lasted for several hours. In addition, she had had three or four episodes of unconsciousness during the previous year, which were preceded on each occasion by blurred vision and giddiness. These episodes lasted from 5 to 15 minutes and were also accompanied by sweating, though no vomiting,

Received January 26, 1967. convulsions, or incontinence were observed. There were no other significant past illnesses.

Her family history was not contributory. She was the only child of her mother's second and her father's first marriage, and she has four normal half-sibs. Her mother was approximately 25 and her father was 28 at the time of her birth. She was adopted in infancy by her paternal grandparents and little is known of the maternal side. Neither parent was available for examination.

Physical examination at the age of 10 years revealed a

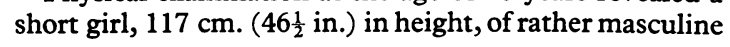

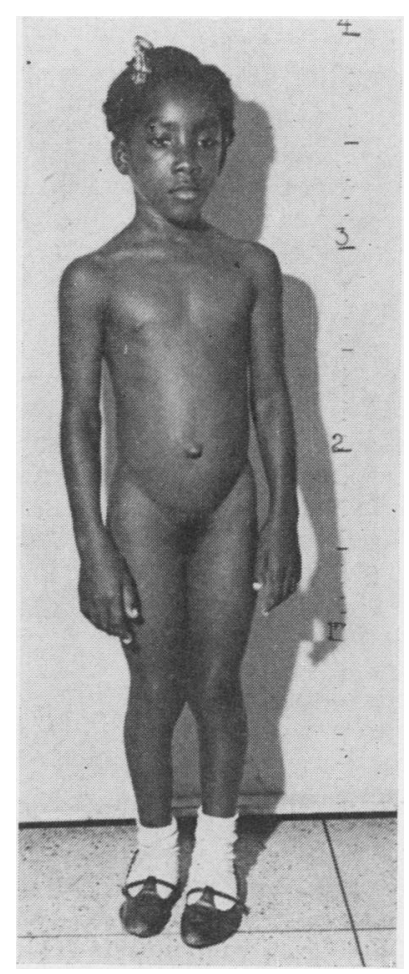

Fig. 1. Patient at age 10 years. 


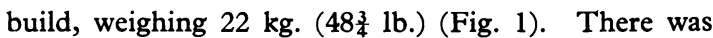
generalized hirsutes and a low posterior hair line. Growth of pubic hair, which had been noted at 6 years, was marked. Skeletal abnormalities included long fingers and absence of the three lateral toes and metatarsals of the right foot. There was a single transverse palmar crease in the right hand. The blood pressure was $100 / 60 \mathrm{~mm} . \mathrm{Hg}$, and there were no abnormalities of the cardiovascular or respiratory systems or the abdomen, except for an umbilical hernia. There was no breast development or axillary hair. The external genitalia were normal except for moderate enlargement of the clitoris. She was of average intelligence and no neurological deficit was elicited. There was a suggestion of cubitus valgus, but there was no webbing of the neck, colour blindness, deafness, or naevi.

Investigations showed a normal 24-hour excretion of urinary 17 -ketosteroids $(0.8$ and $1.4 \mathrm{mg}$.) and ketogenic steroids ( 1.3 and $2.5 \mathrm{mg}$.). The thyroid-binding index was normal $(1 \cdot 07)$ and all other investigations including G6PD deficiency, glucose tolerance test, urine cultures, and urinary porphyrins were negative. A spot blood sugar taken during one of the attacks was $74 \mathrm{mg} . / 100 \mathrm{ml}$. The haemoglobin was AA on electrophoresis.

An electroencephalogram in August 1966 was reported (Dr. V. O. Williams) as showing a grossly abnormal generalized dysrhythmia, with emphasis over the anterior temporal areas, more marked on the right side and consistent with a diagnosis of epilepsy. She has been treated since January 1966 with phenobarbitone $15 \mathrm{mg}$., three times a day, and during this time has had only one attack of vomiting and sweating.

Radiological Findings. Abnormalities were detected in the skeletal system and urinary tract.

There was shortening of the terminal phalanx of the left great toe. The epiphyses of the proximal phalanges of the left foot were triangular in shape and inset into the bases of the adjacent metaphyses. The right foot was severely malformed, there being only two digits and abnormal development of the tarsal bones, with a single cuneiform and a large, abnormally shaped cuboid. Radiographs of the knees showed prominence of the medial femoral condyles and depression of the medial tibial condyles.

Excretion pyelography revealed dilatation and clubbing of the upper calyces of the right kidney without any visible loss of renal cortex. A micturating cystourethrogram showed no evidence of vesico-ureteric reflux.

Radiographs of the chest, shoulders, long bones, spine, and pelvis were negative. The skull also appeared normal though the cranial capacity (estimated by a modification of the McKinnon formula (Gordon, 1966) was small, measuring only $1200 \mathrm{ml}$. (normal range 1250$1575 \mathrm{ml}$.); the significance of this finding is uncertain.

We only recently learned that the family emigrated to the United States in September 1966, so laparotomy to determine the nature of the gonads has not been performed.
Cytogenetic Findings. Buccal smears on two occasions showed $4 \%$ and $5 \%$ of cells with a single Barr body. Peripheral blood was cultured on two occasions by the microtechnique of Arakaki and Sparkes (1963), the first time for chromosome analysis and the second time for autoradiographic studies. In both cultures two cell lines were detected. The first line, making up about $60 \%$ of the count, showed 45 chromosomes with a missing $\mathrm{C}$ chromosome. The second line, totalling approximately $30 \%$ of the cells, contained 46 chromosomes, but one of the group $\mathrm{C}$ chromosomes was replaced by a large submetacentric chromosome similar in appearance to a No. 2 , but with slightly longer long arms and a suggestion of a secondary constriction in some cells (Fig. 2a and b). In the second culture, tritiated thymidine was added $3 \frac{1}{2}$ hours before termination of the culture. The air-dried smears were immersed in emulsion and exposed for three days, then stained with Giemsa. In about $30 \%$ of the cells which had 46 chromosomes the abnormal submetacentric chromosome was heavily labelled as in Fig. 3. However there was no evidence of a late-labelling chromosome in any of the 45 chromosome cells. Heavy labelling of the large submetacentric chromosome was not confined to one part of it but appeared to be over the entire length. This suggests strongly that most of this chromosome was derived from a $\mathrm{X}$ chromosome.

\section{Discussion}

There are several unusual aspects to this patient, from the clinical, radiological, and cytogenetic standpoints.

Clinically, the findings suggest three possible diagnoses, Turner's syndrome, congenital adrenal hyperplasia, or virilization of hormonal or chromosomal origin. We consider that the stunting of growth and the skeletal and renal abnormalities fit most nearly into the pattern of Turner's syndrome, though we have not been able to confirm histologically the presence of gonadal dysgenesis. Virilization has been observed in occasional cases with gonadal dysgenesis, though Ferguson-Smith (1965) found it most frequently in cases with an abnormally small sex chromosome thought possibly to be of $Y$ chromosome origin; phallic hypertrophy alone also occurred in about a quarter of the patients with a deletion of the long arm of the X. Adrenal hyperplasia or a virilizing tumour was excluded by the normal levels of ketosteroids.

A virilizing syndrome due to the presence of $Y$ chromosome material is also a possibility. This would be favoured by the presence of testicular tissue which again we have been unable to ascertain. We have not demonstrated a $\mathrm{Y}$ chromosome, but only one tissue has been examined. Epilepsy, probably of temporal lobe origin, has not to our knowledge been previously reported in association 


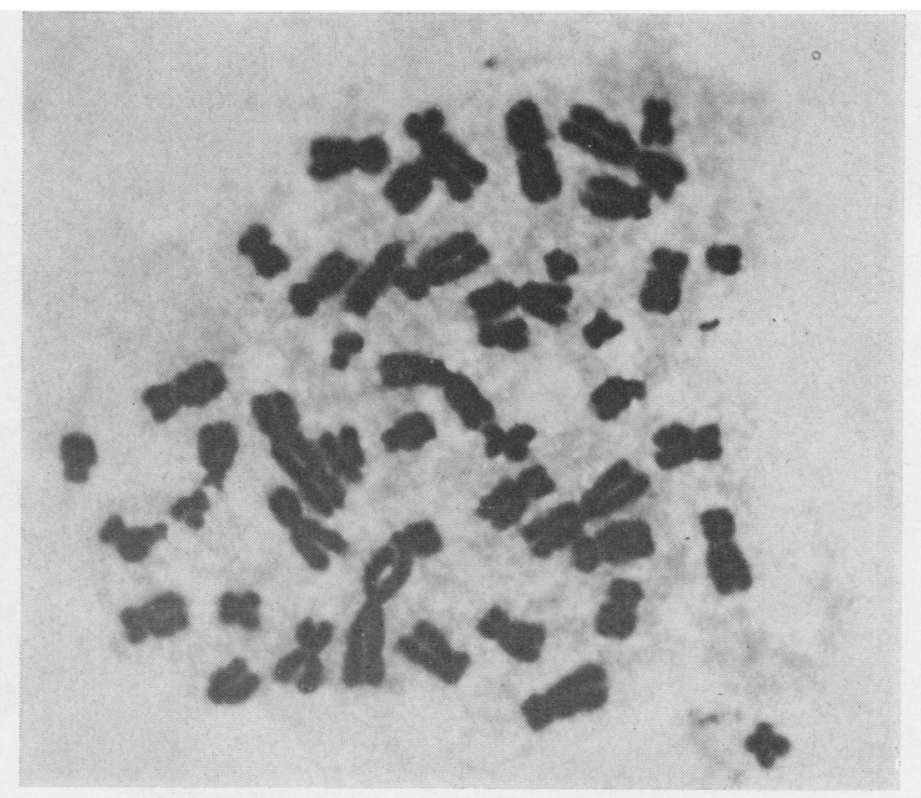

with any of these conditions. There is no family history of epilepsy, as far as can be ascertained and we have no explanation for it other than a fortuitous association.

On analysis of the radiological findings, the changes in the knees are typical of Turner's syndrome and are similar to those described by Kosowicz (1960) and Keats and Burns (1964). Other typical features, such as increased translucency of the skeleton, delay in closure of epiphysial lines, 


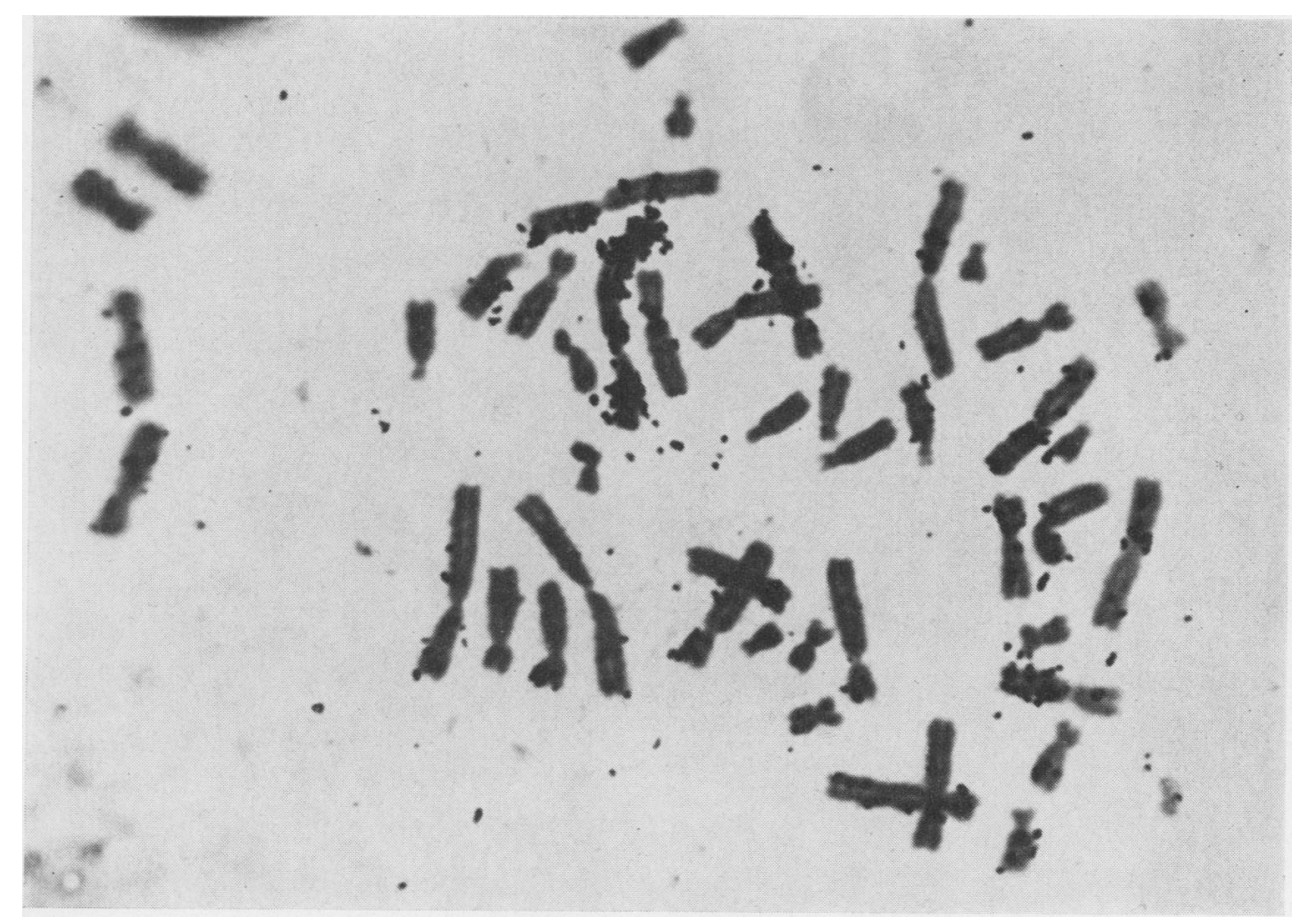

FIG. 3. Metaphase spread, with labelling of the abnormal chromosome.

short fourth metacarpals, spinal osteochondrosis, maldevelopment of ribs and clavicles, and male configuration of the pelvis were absent.

The changes in the hand and feet were unusual. The epiphysial abnormality of the phalanges of the left foot resembled that commonly seen in haemoglobinopathy (Middlemiss, 1961), but this was excluded in this patient. Similar appearances have been described in gonadal dysgenesis by Keats and Burns (1964). Finby and Archibald (1963) state that fused carpal bones, short phalanges, and partial absence of digits may be seen.

The appearances shown on excretion urography were interesting. Renal anomalies associated with gonadal dysgenesis are well recognized, malrotation of the kidneys being the commonest (Hortling, 1955; Levin, 1962; Astley, 1963). Hortling (1955) also noted the incidence of horseshoe kidneys and double ureters and pelves. In a recent paper, Hung and LoPresti (1965) found renal abnormalities in 8 out of 9 patients with gonadal dysgenesis. Malrotation was the commonest anomaly but horseshoe kidney and also mild hydronephrosis due to pelvi-ureteric obstruction were seen. The calyceal dilatation in this case could be due to pyelonephritis though there was no clinical confirmation of this at the time of examination. There was no radiological evidence of obstruction.

Cytogenetically, the morphological abnormality resembles in appearance that described by Wie Lie et al. (1964), though the presence of mosaicism has modified the picture so that it is not possible to draw any further parallels. Clinically, the cases differ considerably. It seems most likely that the abnormal chromosome in the 46 cells is of mainly $\mathrm{X}$ chromosome origin. The evidence in favour of this is strong. First, the small proportion of cells with sex chromatin is suggestive of a small line with $2 \mathrm{X}$ chromosomes, but no 46 cells were found with a full normal complement in the $\mathrm{C}$ group. Secondly, the association with an XO line is frequently seen in morphological abnormalities of the X. Thirdly, there is no evidence from the karyotypes of any translocation with an autosome. Fourthly, it would be most unlikely to find such a gross autosomal abnormality without far more phenotypic disturbance, especially mental retardation. Lastly, autoradiographic study shows that the abnormal chromosome always labels late, and appears to be uniformly labelled. No cells were seen in which a normal-sized chromosome labelled late. The origin of this abnormal chromosome is very difficult 
to explain. The size of the shorter arm is approximately the same as the long arm of the normal X; this suggests that it could be either an isochromosome of the long arm with an extra translocated segment or a normal $\mathrm{X}$ with extra material. Either way, the sequence of events leading to its formation would be complex. In none of the 45 cells was there detected a small fragment which would suggest a post-zygotic rearrangement of $\mathrm{X}$ chromosomal material, though it is possible that such a fragment and the large chromosome may have been lost from a proportion of the cells.

\section{Summary}

A 10-year-old girl with short stature, some degree of masculinization, and attacks of temporal lobe epilepsy, was found to have some unusual radiological features and to have sex chromosomal mosaicism. A $45 \mathrm{XO}$ line and a line with 46 chromosomes containing a large submetacentric, thought to be of $\mathrm{X}$ chromosome origin, were found on culture of the peripheral blood, and buccal smears showed a small proportion of sex chromatin positive cells. The mode of origin of the abnormal chromosome and the possibility of hermaphroditism is discussed, but it is felt that in the absence of information about the gonads, the clinical picture fits most nearly into the spectrum of gonadal dysgenesis.

We acknowledge the assistance of Mr. Colin Benjamin in producing the autoradiographs. Pure Heparin B.P. was provided by Boots Pure Drug Company, Nottingham, England.

The cytogenetic work is supported by grants from the Wellcome Trust and from the Standing Advisory Committee for Medical Research in the Caribbean.

\section{REFERENCES}

Arakaki D. T., and Sparkes, R. S. (1963). Microtechnique for culturing leukocytes from whole blood. Cytogenetics, 2, 57.

Astley, R. (1963). Chromosomal abnormalities in childhood with particular reference to Turner's syndrome and mongolism. Brit. 7. Radiol., 36, 2.

Engel, E., and Forbes, A. P. (1965). Cytogenetic and clinical findings in 48 patients with congenitally defective or absent ovaries. Medicine (Baltimore), 44, 135.

Ferguson-Smith, M. A. (1965). Karyotype-phenotype correlations in gonadal dysgenesis and their bearing on the pathogenesis of malformations. $\mathcal{F}$. med. Genet., 2, 142.

Finby, N., and Archibald, R. M. (1963). Skeletal abnormalities associated with gonadal dysgenesis. Amer. F. Roentgenol., 89, 1222.

Gordon, I. R. S. (1966). Measurement of cranial capacity in children. Brit. F. Radiol., 39, 377.

Hortling, H. (1955). Congenital kidney anomalies in 'Turner's syndrome'. Acta endocr. (Kbh.), 18, 548.

Hung, W., and LoPresti, J. M. (1965). Urinary tract anomalies in gonadal dysgenesis. Amer. F. Roentgenol, 95, 439.

Keats, T. E., and Burns, T. W. (1964). The radiographic manifestations of gonadal dysgenesis. Radiol. Clin. N. Amer., 2, 297.

Kosowicz, J. (1960). Deformity of the medial tibial condyle in 19 cases of gonadal dysgenesis. F. Bone ft Surg., 42A, 600.

Levin, B. (1962). Gonadal dysgenesis: clinical and roentgenologic manifestations. Amer. F. Roentgenol, 87, 1116.

Mann, J. D., Valdmanis, A., Capps, S. C., and Puite, R. H. (1965). A case of primary amenorrhea with a translocation involving chromosomes of groups B and C. Amer. F. hum. Genet., 17, 377.

Middlemiss, J. H. (1961). Tropical Radiology, p. 84. Heinemann, London.

Wie Lie, G., Coenegracht, J. M., and Stalder, G. (1964). A very large metacentric chromosome in a woman with symptoms of Turner's syndrome. Cytogenetics, $3,427$. 